\title{
Combination Dyeing of Juniperus Chinensis Heartwood and Alnus Japonica Heartwood Extracts
}

\author{
A-Na Sa and Jung Soon Lee ${ }^{\dagger}$ \\ Dept. of Clothing and Textiles, Chungnam National University; Daejeon, Korea
}

\begin{abstract}
The purpose of this study was to examine improvements in dye uptake, expression of various colors, and color fastness when washed or exposed to light. We examined these improvements by doing the combination dyeing of Juniperus chinensis heartwood and Alnus japonica heartwood extracts. In this study, two combination dyeing methods were used. One-bath dyeing involves combining Juniperus chinensis heartwood extract and Alnus japonica heartwood extract. Two-bath dyeing involves dyeing by sequence, which means that we dyed the Juniperus chinensis heartwood extract first and then dyed Alnus japonica heartwood extract sequentially (or in the opposite order). In terms of improving dye uptake, two-bath dyeing was more effective than one-bath dyeing. For cotton, dyeing Juniperus chinensis heartwood extract first and then dyeing Alnus japonica heartwood extract sequentially showed higher dye uptake in the two-bath method, while for silk, there wasn't much difference in the dyeing order. Through combination dyeing, red-violet color from Juniperus chinensis heartwood and brown color from Alnus japonica heartwood made various Y, YR, R series of color as a result. Moreover, combination dyeing improved fabric's fastness when washed or exposed to light. In the case of cotton, fabric dyed using two-bath dyeing, with Juniperus chinensis heartwood extract being the first dye, showed improvement in fastness to washing and light. And in the case of silk, fastness to washing and light improved regardless of dyeing order in two-bath dyeing.
\end{abstract}

Key words : Juniperus chinensis heartwood, Alnus japonica heartwood, combination dyeing, washing fastness, light fastness

\section{Introduction}

Due to recent social background of strict regulation and awareness toward environment and eco-friendly social trend, natural dyeing is gaining popularity(Park, 2012). Via natural dyeing, gorgeous colors that can't be achieved through synthetic dyestuff can be produced, and environmental pollution can be prevented since it uses natural stuff. Also, it's human body-friendly and has many good aspects including functions such as antibacterial effect and insectproof effect(Noh \& Lee, 2014). However, its base material is limited, and there is difficulty in extracting pigment and expressing variety of colors. Also, it's hard to reproduce same color, and generally has low fastness. Because of these, use of natural dyeing is limited compared to synthetic dyeing(Kang et al., 2011; Yoo et al., 2014).

In order to supplement shortages in color revelation of natural dyeing, using mordant during dyeing process or combination dyeing of natural dyestuff can be considered(Lim et al., 2001). Until now, there have been many researches on combination dyeing of

$\uparrow$ Corresponding author; Jung Soon Lee

Tel. +82-42-821-6830, Fax. +82-42-821-8887

E-mail: jungsoon@cnu.ac.kr various dye stuff, and if they are classified by color, there was combination dyeing of similar series of color dye stuff(Kim, 2009; Nam \& Lee, 2013), of yellow and blue dye stuff(Bae, 2009; Jung \& Sul, 2002; Oh et al., 2008), of red and yellow dye stuff(Bae, 2005; Jung \& Jang, 2004), of red, yellow, and blue dye stuff(Shin, 2012; Yoo \& Lee, 2003), of red, yellow, and black dye stuff(Park \& Yoon, 2011), and other color dye stuffs(Yoo \& Lee, 2001).

Combination dyeing can be a way of seeking color diversity of dyed products and improving fastness(Jung, 2008; Kim, 2010; Noh $\&$ Yu, 2002; Sa et al., 2014). Easier the dye stuffs gather, and higher the concentration of dye stuff that is absorbed in the fabric, light fastness increases. There can be difference in degree, and it's related to size of gathering of dye stuff(Giles, 1957). Combination dyed fabric might have different form of gathering status of dye stuff from single dyed fabric, so there needs to be examination on light fastness(Jung \& Jang, 2004).

Juniperus chinensis is evergreen coniferous plant of the family Cupressaceae, and it is used as medicine in folk remedy and oriental medicine due to its good antibiotic, insect-proof function. It is also used as herb to eliminate bad odors(Hwang, 1994; Kim, 2001). Juniperus chinensis heartwood extract has essential oil component such as terpene(Fang et al., 1996), and it has santalin, non-aqueous red dye, other than tannin, so it produces vivid red-violet color. 
Table 1. Characteristics of fabrics

\begin{tabular}{ccccccc}
\hline Fabric & $\begin{array}{c}\text { Fiber } \\
\text { composition }\end{array}$ & Weave & $\begin{array}{c}\text { Fineness } \\
(\text { Warp } \times \text { Weft })\end{array}$ & $\begin{array}{c}\text { Weight } \\
\left(\mathrm{g} / \mathrm{m}^{2}\right)\end{array}$ & $\begin{array}{c}\text { Thickness } \\
(\mathrm{mm})\end{array}$ & $\begin{array}{c}\text { Fabric count warp } \times \text { weft } \\
(5 \mathrm{~cm} \times 5 \mathrm{~cm})\end{array}$ \\
\hline Cotton & $100 \%$ cotton & plain & 30 's $\times 30$ 's & $102 \pm 5$ & $0.29 \pm 0.02$ & $145 \times 134$ \\
Silk & $100 \%$ silk & plain & $54 \mathrm{D} \times 54 \mathrm{D}$ & $57 \pm 2$ & $0.13 \pm 0.05$ & $268 \times 220$ \\
\hline
\end{tabular}

Therefore, Juniperus chinensis heartwood extract can be used as effective natural dye stuff that manifests red-violet series color with various functions(Nam \& Lee, 2013; Tennakone et al., 1998).

Alnus japonica is deciduous tree of the family Betulaceae, and it is known that there are lots of phenolic compounds such as flavonoid and tannin in hot water extraction of Alnus japonica(Seo, 2003). If mordant is not used, it produces soft brown color, and by using various mordant, light brown, dark brown, and jade green color can be manifested(Sa et al., 2013). Tannin, one of the components of Alnus japonica extract, have been used mainly as black dyeing of silk, mordant of cotton, and oiling agent of leather, and is also used to improve washing fastness. Moreover, tannin works as preservative when it interacts with sunlight, so it restrains decay of fabric, and it makes fabric stiff without starching, improving air permeability at the same time(Kim, 2001; Sul \& Choi, 1999).

Thus, in this study, improvements in dye uptake and change in color were examined by performing combination dyeing using Juniperus chinensis extract and Alnus japonica extract, and improvements in color fastness were evaluated by looking at color difference after washing and UV irradiation.

\section{Experiment}

\subsection{Materials}

Juniperus chinensis heartwood and Alnus japonica heartwood used in this experiment are bought from medical herb store in the open market. Fabrics used in the experiment are 100\% cotton, scoured and bleached silk, and their properties are shown in Table 1.

\subsection{Dye Extraction}

1) Dye extraction of Juniperus chinensis heartwood

The ratio of Juniperus chinensis heartwood to ethanol being 1:7, Juniperus chinensis heartwood was soaked in ethanol for 48 hours at room temperature before extraction. This process was repeated 3 times. Extract was filtered 3 times until no sediment was found, and it was concentrated by decompression at 40 60 and $180 \mathrm{rpm}$ using rotary vacuum evaporator(RV10, IKA, Germany). Then, it was vacuum dried and powder form of dye was used in the experiment.

\section{2) Dye extraction of Alnus japonica heartwood}

The ratio of Alnus japonica heartwood(940 g) to ethanol being
$1: 5$, pigment was extracted for 60 minutes at $100 \mathrm{c}$, and this process was repeated 3 times. Gained pigment was concentrated to $1000 \mathrm{ml}$, and was filtered until no sediment was found. $100 \%$ of dyeing solution was used in the experiment.

\subsection{Combination Dyeing}

There are one-bath and two-bath dyeing in combination dyeing. In one-bath dyeing, different dyes are mixed together in appropriate ratio, and are dyed simultaneously. On the other hand, in twobath dyeing, each dye is used separately, by dyeing using first dye and then dyeing again with the other dye sequentially(Jung \& Jang, 2004). These two types of method are both applied to combination dyeing of Juniperus chinensis heartwood and Alnus japonica heartwood, and those are shown in Table 2. Infrared dyeing machine (ACE-6000T, ACE Corp. KOREA) was used. When implementing one-bath dyeing, dye solution ratio of Juniperus chinensis heartwood and Alnus japonica heartwood extracts was 50:50. When implementing two-bath dyeing, 2 sequence of dyeing(dyeing Juniperus chinensis heartwood extract first and then dyeing Alnus japonica heartwood extract, and dyeing in the opposite order) was tried. Previous research(Nam \& Lee, 2013; Sa et al., 2013) is referred in setting dyeing condition, and it is shown in Table 3.

Table 2. Descriptions of the dyeing method

\begin{tabular}{cl}
\hline $\begin{array}{c}\text { Dyeing } \\
\text { abbreviation }\end{array}$ & \multicolumn{1}{c}{ Description } \\
\hline Juniperus & $\begin{array}{c}\text { Dyeing Juniperus chinensis extract } \\
\text { Dyeing Alnus japonica } \text { extract }\end{array}$ \\
Alnus & $\begin{array}{c}\text { Dyeing Juniperus chinensis and Alnus } \\
\text { japonica } \text { extracts simultaneously }\end{array}$ \\
Juniperus+Alnus & $\begin{array}{l}\text { Dyeing Juniperus chinensis } \text { and Alnus } \\
\text { japonica } \text { extracts sequentially }\end{array}$ \\
& $\begin{array}{l}\text { Dyeing } \text { Alnus japonica } \text { and Juniperus } \\
\text { chinensis } \text { extracts sequentially }\end{array}$ \\
\hline
\end{tabular}

Table 3. Dyeing conditions

\begin{tabular}{cccccc}
\hline \multirow{2}{*}{ Method } & $\begin{array}{c}\text { Conc. } \\
(\%)\end{array}$ & $\begin{array}{c}\text { Temp. } \\
\left({ }^{\circ} \mathrm{C}\right)\end{array}$ & $\begin{array}{c}\text { Time } \\
(\mathrm{min})\end{array}$ & $\begin{array}{c}\text { Liquor } \\
\text { ratio }\end{array}$ \\
\hline \multirow{2}{*}{ Dyeing } & Juniperus & $0.5($ o.w.b) & 60 & 30 & $1: 50$ \\
& Alnus & $20,40.60,80$ & 80 & 60 & $1: 50$ \\
& Juniperus+Alnus & $50: 50$ & 70 & 45 & $1: 50$ \\
\hline
\end{tabular}




\subsection{Measuring dye uptake and surface color}

A color reader(JS-555, C.T.S Corp., Japan) was used to estimate physical properties of color, CIELAB properties, and the estimated color values were used to obtain $\mathrm{H} \mathrm{V/C}$ values for the Munsell color system. To measure dye uptake, $\mathrm{K} / \mathrm{S}$ was calculated in Kubelka-Munk way by measuring surface reflectance at dyeing fabric's maximum absorption wavelength $(400 \mathrm{~nm})$.

$K / S=\frac{(1-R)^{2}}{2 R}$

Each letter refers to,

$K$ : absorption coefficient

$S$ : scattering coefficient

$R$ : reflectance coefficient $(0<\mathrm{R} \leq 1)$

\subsection{Washing}

Dyed fabric was washed for 5 minutes using shaking apparatus under the condition of constant temperature of $20^{\circ} \mathrm{C}$, at the speed of $85 \mathrm{rpm}$, with the solution of $0.2 \%$ (o.w.b) neutral detergent available on the market. After washing, it was washed again with hands and was naturally dried. This was carried out 5 times repeatedly.

\subsection{UV irradiation}

UV-C lamp examination time was set differently from 0 minute to 100 minute, time varying by 20 minutes as a unit. Used UV examination equipment was the one that was privately made. This UV examination equipment's UV-C lamp examination time of 5 minutes corresponds to 1 hour based on the examination time calculated using solar thermal energy at noon of midsummer, at latitude $40^{\circ}$, meridian 20 (Choi \& Lee, 2005).

\subsection{Calculating $\Delta \mathrm{E}$ value of dyed fabric}

Color difference(hereinafter, $\Delta \mathrm{E}$ ) was calculated using dyed fabric before washing and UV irradiation as a standard. $\mathrm{L}, \mathrm{a}^{*}, \mathrm{~b}^{*}$ value was calculated 4 times and their average value was used.

$$
\Delta E=\sqrt{(\Delta L)^{2}+\left(\Delta a^{*}\right)^{2}+\left(\Delta b^{*}\right)^{2}}
$$

Each letter refers to,

$\mathrm{L}^{*}$ : refers to brightness, relation between white and black

$a^{*}$ : relation between red and green

$\mathrm{b}^{*}$ : relation between yellow and blue

\section{Results and Discussion}

\subsection{Dye uptake according to methods of combination} dyeing

Fig. 1 and Fig. 2 show dye uptake(dyeing volume) of cotton and silk which are combination dyed with Juniperus chinensis heartwood extract and Alnus japonica heartwood extract using one-bath and two-bath dyeing.

In terms of cotton, dye uptake was highest when it was dyed with Juniperus chinensis heartwood extract first and then dyed with Alnus japonica heartwood extract, K/S value being $0.946 \sim 1.822$. It was same with the silk, $\mathrm{K} / \mathrm{S}$ value being 2.801 7.591. Regarding cotton, this method and order of dyeing resulted in much higher dye uptake than the other method of dyeing in the opposite order(dyeing Alnus japonica heartwood extract first and then dyeing Juniperus chinensis heartwood extract). However, regarding silk, there wasn't much difference between the two methods. This is related to chemical structure of dyed fabric and dyeing solution. Cellulose fiber takes on negative charge while bathing, and tannin has plentiful hydroxyl group $(-\mathrm{OH})$. Therefore, electrical resistance happens between the two, resulting weak coherence in cotton and tannin(Shin \& Choi, 1999). Because of this, Juniperus chinensis heartwood extract has much more influence than Alnus japonica heartwood extract when dyeing cotton, and it is assumed this is why dyeing cotton with Juniperus chinensis heartwood extract first results in higher dye uptake. Generally it is known that dyeing silk using tannin shows significantly high dye uptake around an isoelectric point of silk(Choi \& Kim, 1998). At isoelectric point, positive ion $(+)$ increases in the surface of silk, and then increased positive ions actively combine with negative ions(-) of tannin, and dye uptake becomes high as a result. Isoelectric point of silk is known as pH 3.8-4.0(Lee \& Jang, 2003), and $\mathrm{pH}$ of Juniperus chinensis heartwood extract is 4.5 , and $\mathrm{pH}$ of Alnus japonica heartwood extract is 4.85 , so both are around isoelectric point. Therefore, positive ion $(+)$ on the surface of silk actively combines with negative ion(-) of both Juniperus chinensis

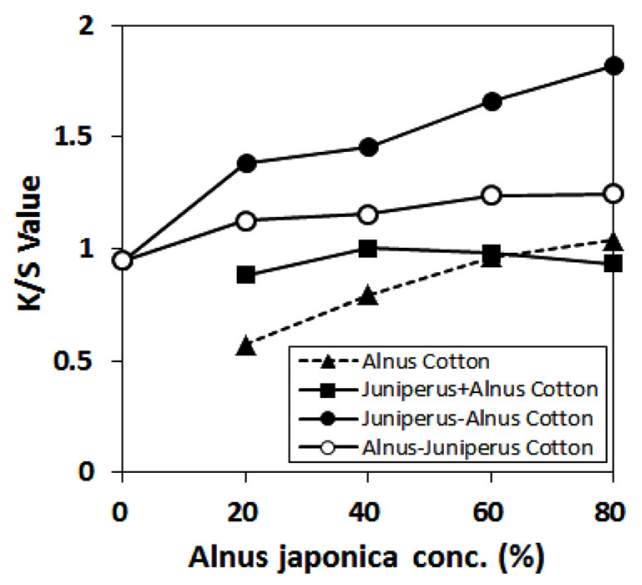

Fig. 1. Effect of combination dyeing method on the dye uptake of dyed cotton fabrics with Juniperus chinensis and Alnus japonica extracts. 


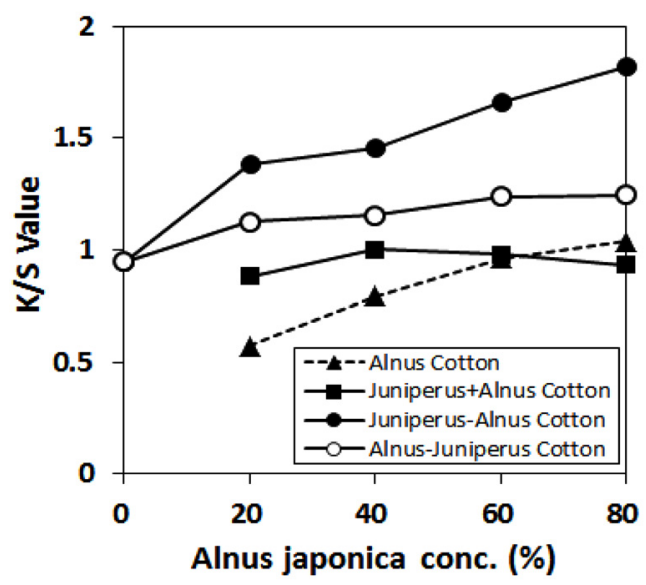

Fig. 2. Effect of combination dyeing method on the dye uptake of dye silk fabrics with Juniperus Chinensis and Alnus japonica extracts.

heartwood extract and Alnus japonica heartwood extract, making not much difference in the dyeing orders in method 2, and both method resulted in high dye uptake.

Combination dyeing using one-bath dyeing showed lower value than using two-bath. In terms of one-bath dyeing, not only speed of dye uptake but also compatibility between 2 dyes materials should be considers to get the preferable color(Jung \& Jang, 2004). Tannin of Alnus japonica heartwood extract is hydrolyzable tannin(Sa et al., 2013), while tannin of Juniperus chinensis heartwood extract is condensed tannin(Nam \& Lee, 2012). Hydrolyzable tannin's molecule bulk is smaller than condensed tannin, and has structurally higher mobility. In one-bath dyeing, mobility of hydrolyzable tannin of Alnus japonica heartwood extract is higher(Sul et al., 1995), so it is absorbed first, weakening influence of Juniperus chinensis heartwood extract, resulting low dye uptake. This result matches the result of other study in which combination dyeing using Juniperus chinensis heartwood extract, condensed tannin, and Terminalia Chebula Retzius extract, hydrolyzable tannin, was carried out and one-bath dyeing resulted in lower dye uptake than two-bath dyeing(Sa et al., 2014).

\subsection{Surface color change according to methods of combination dyeing}

1) One-bath dyeing mixed solution of Juniperus chinensis heartwood and Alnus japonica heartwood extracts

Table 4 refers to surface color change of cotton and silk dyed with mixed solution of Juniperus chinensis heartwood and Alnus japonica heartwood extracts. Munsell color value $(\mathrm{H})$ of these dyed fabrics all showed $\mathrm{Y}$ series color, which shows fabrics are influenced by hydrolyzable tannin of Alnus japonica heartwood extract first. As concentration of Alnus japonica heartwood extract increased, $a^{*}$ value of cotton decreased a little, and a value of silk increased a bit, but $b^{*}$ value of both fabrics increased a lot, so reddish color decreased while yellowish color increased

2) Two-bath dyeing Juniperus chinensis heartwood and Alnus japonica heartwood extracts sequentially

Table 5 refers to surface color change of cotton and silk dyed with Juniperus chinensis heartwood extract and Alnus japonica heartwood extract sequentially. Cotton and silk dyed only with Juniperus chinensis heartwood extract showed red-violet color of $\mathrm{R}$ series, but when dyed with Juniperus chinensis heartwood extract first and then dyed again with Alnus japonica heartwood extract sequentially, it showed Y series color. As concentration of Alnus japonica heartwood extract increased, both cotton and silk showed decrease in $a^{*}$ value and increase in $b^{*}$ value, which refers to decrease in reddish color and increase in yellowish color. Rate of change was relatively greater in $\mathrm{b}^{*}$ value than $\mathrm{a}^{*}$ value, so it can be concluded that the higher concentration of Alnus japonica heartwood extract results in more influence of Alnus japonica heartwood extract, which makes Y series color.

Table 4. Color characteristics of cotton and silk fabrics after dyeing Juniperus chinensis and Alnus japonica extracts simultaneously(one bath dyeing)

\begin{tabular}{|c|c|c|c|c|c|c|c|}
\hline Fabric & Alnus japonicaconc.(\%) & $\mathrm{L}^{*}$ & $a^{*}$ & $\mathrm{~b}^{*}$ & $\mathrm{H}$ & $\mathrm{V} / \mathrm{C}$ & Color image \\
\hline \multirow{5}{*}{ Cotton } & 0 & 64.01 & 12.26 & -0.756 & $3.852 \mathrm{R}$ & $6.231 / 2.214$ & in \\
\hline & 20 & 67.22 & 10.41 & 3.286 & $2.108 \mathrm{Y}$ & $6.555 / 1.955$ & \\
\hline & 40 & 66.43 & 10.20 & 5.191 & $3.808 \mathrm{Y}$ & $6.475 / 2.087$ & \\
\hline & 60 & 67.24 & 10.03 & 5.865 & $4.476 \mathrm{Y}$ & $6.557 / 2.132$ & \\
\hline & 80 & 68.46 & 9.291 & 6.499 & $5.872 \mathrm{Y}$ & $6.681 / 2.087$ & \\
\hline \multirow{5}{*}{ Silk } & 0 & 48.83 & 18.37 & 3.096 & $4.205 \mathrm{R}$ & $4.734 / 3.480$ & \\
\hline & 20 & 53.41 & 15.89 & 9.827 & $1.279 \mathrm{Y}$ & $5.180 / 3.464$ & \\
\hline & 40 & 52.30 & 16.64 & 12.22 & $2.056 \mathrm{Y}$ & $5.072 / 3.812$ & \\
\hline & 60 & 48.36 & 17.15 & 13.09 & $2.153 \mathrm{Y}$ & $4.689 / 3.892$ & \\
\hline & 80 & 49.80 & 16.58 & 14.65 & $3.151 \mathrm{Y}$ & $4.828 / 4.003$ & \\
\hline
\end{tabular}


Table 5. Color characteristics of cotton and silk fabrics after dyeing Juniperus chinensis and Alnus japonica extracts sequentially(two bath dyeing)

\begin{tabular}{cccccccc}
\hline Fabric & Alnus japonicaconc.(\%) & $\mathrm{L}^{*}$ & $\mathrm{a}^{*}$ & $\mathrm{~b}^{*}$ & $\mathrm{H}$ & $\mathrm{V} / \mathrm{C}$ & Color image \\
\hline \multirow{4}{*}{ Cotton } & 0 & 64.01 & 12.26 & -0.756 & $3.852 \mathrm{R}$ & $6.231 / 2.214$ & \\
& 20 & 62.14 & 7.954 & 7.013 & $7.634 \mathrm{Y}$ & $6.044 / 1.919$ & \\
& 40 & 62.54 & 9.278 & 8.382 & $6.663 \mathrm{Y}$ & $6.085 / 2.275$ & \\
& 60 & 63.09 & 9.274 & 11.56 & $7.947 \mathrm{Y}$ & $6.139 / 2.681$ & \\
\hline \multirow{4}{*}{ Silk } & 80 & 62.99 & 9.132 & 13.26 & $8.477 \mathrm{Y}$ & $6.129 / 2.893$ & \\
& 0 & 48.83 & 18.37 & 3.096 & $4.205 \mathrm{R}$ & $4.734 / 3.480$ & \\
& 40 & 47.37 & 16.10 & 13.20 & $2.855 \mathrm{Y}$ & $4.592 / 3.716$ & \\
& 40 & 45.85 & 16.18 & 16.53 & $4.104 \mathrm{Y}$ & $4.446 / 4.036$ & \\
& 60 & 45.97 & 16.02 & 18.00 & $4.661 \mathrm{Y}$ & $4.457 / 4.167$ & \\
\hline
\end{tabular}

3) Two-bath dyeing Alnus japonica heartwood and Juniperus chinensis heartwood extracts sequentially

Table 6 refers to surface color change of cotton and silk dyed with Alnus japonica heartwood extract and Juniperus chinensis heartwood extract sequentially. In terms of cotton, it maintains $\mathrm{R}$ series color even when the concentration of Alnus japonica heartwood extract increases. However, dyed silk presents YR series color when concentration of Alnus japonica heartwood extract is up to $40 \%$, and it presents $\mathrm{Y}$ series color when the concentration is over $60 \%$. Therefore, through this type of dyeing method, dyeing Alnus japonica heartwood extract first and then dyeing Juniperus chinensis heartwood extract sequentially, YR series color which can't be achieved through other methods of combination dyeing can be achieved. $\mathrm{a}^{*}$ value barely changed in cotton, and only $\mathrm{b}^{*}$ value increased a bit. Regarding silk, as concentration of Alnus japonica heartwood extract increased, $\mathrm{a}^{*}$ value decreased and $\mathrm{b}^{*}$ value increased which refers to decrease in reddish color and increase in yellowish color.

Cotton is cellulose fiber, so it takes on negative charge(-) in aqueous solution. Tannin in Alnus japonica heartwood extract has plentiful hydroxyl group(-OH) and also has negative charge(-).
Therefore, resistance happens between cotton fiber and tannin, which results in low dyeing property(Shin \& Choi, 1999). Because of this, cotton is influenced more by red-violet color from Juniperus chinensis heartwood extract rather than tannin of Alnus japonica heartwood extract, and shows reddish color. On the other hand, silk is protein fiber and has plentiful amino group $\left(-\mathrm{NH}_{2}\right)$, so it takes on positive charge in aqueous solution. It actively combines with tannin's hydroxyl group(-OH) which results in high dye uptake(Han et al., 2006). Therefore, when silk is dyed with Alnus japonica heartwood extract first and then dyed with Juniperus chinensis heartwood extract sequentially, tannin from Alnus japonica heartwood is already absorbed much in silk, and this blocks red coloring of Juniperus chinensis heartwood extract and increases $b^{*}$ value.

Fig. 3 shows changes in $\mathrm{a}^{*}, \mathrm{~b}^{*}$ values according to 5 kinds of dyeing method and order. These 5 kinds include dyeing mixed solution of Juniperus chinensis heartwood and Alnus japonica heartwood extracts, dyeing Juniperus chinensis heartwood extract and Alnus japonica heartwood extract sequentially, dyeing Alnus japonica heartwood and Juniperus chinensis heartwood extract sequentially, dyeing Juniperus chinensis heartwood extract only,

Table 6. Color characteristics of cotton and silk fabrics after dyeing Alnus japonica and Juniperus chinensis extracts sequentially(two bath dyeing)

\begin{tabular}{|c|c|c|c|c|c|c|c|}
\hline Fabric & Alnus japonicaconc.(\%) & $\mathrm{L}^{*}$ & $\mathrm{a}^{*}$ & $b^{*}$ & $\mathrm{H}$ & $\mathrm{V} / \mathrm{C}$ & Color image \\
\hline \multirow{5}{*}{ Cotton } & 0 & 64.01 & 12.26 & -0.756 & $3.852 \mathrm{R}$ & $6.231 / 2.214$ & \\
\hline & 20 & 62.99 & 12.89 & 1.279 & $6.628 \mathrm{R}$ & $6.129 / 2.372$ & \\
\hline & 40 & 62.56 & 12.49 & 1.434 & $7.164 \mathrm{R}$ & $6.086 / 2.278$ & \\
\hline & 60 & 61.88 & 12.52 & 2.344 & $8.272 \mathrm{R}$ & $6.019 / 2.310$ & \\
\hline & 80 & 61.69 & 12.45 & 2.217 & $8.161 \mathrm{R}$ & $5.999 / 2.290$ & 국 \\
\hline \multirow{5}{*}{ Silk } & 0 & 48.83 & 18.37 & 3.096 & $4.205 \mathrm{R}$ & $4.734 / 3.480$ & \\
\hline & 20 & 48.58 & 15.65 & 12.56 & 2.849YR & $4.709 / 3.611$ & \\
\hline & 40 & 47.89 & 15.88 & 15.70 & $3.966 \mathrm{YR}$ & $4.643 / 3.958$ & \\
\hline & 60 & 46.75 & 15.67 & 17.56 & $4.718 \mathrm{Y}$ & $4.532 / 4.091$ & int \\
\hline & 80 & 44.24 & 15.98 & 17.87 & $4.648 \mathrm{Y}$ & $4.290 / 4.103$ & \\
\hline
\end{tabular}




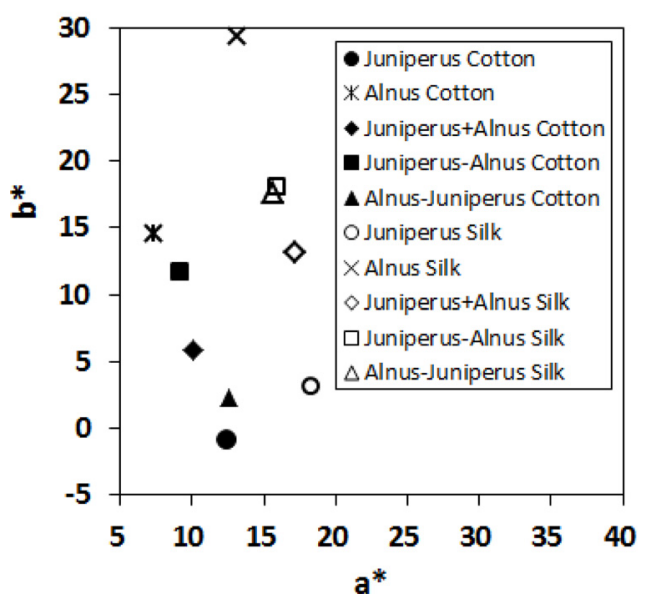

Fig. 3. Hunter's $a^{*}, b^{*}$ value of the combination dyed fabrics with Juniperus chinensis and $60 \%$ Alnus japonica extracts.

and dyeing Alnus japonica heartwood extract only. Variations in $a^{*}, b^{*}$ values were examined in order to find out most suitable method and order of dyeing to improve dye uptake and to achieve wanted surface color series at the same time when implementing combination dyeing. By looking at variations in $a^{*}, b^{*}$ values according to the dyeing order, it was found that for cotton, in order to improve dye uptake and to emphasize R series color on the surface, it is desirable to dye Alnus japonica heartwood and Juniperus chinensis heartwood extract sequentially, and in order to improve dye uptake and to emphasize Y series color on the surface, it is desirable to dye Juniperus chinensis heartwood extract and Alnus japonica heartwood extract sequentially. However, for silk, dyeing order in method 2(2 bath dyeing) didn't matter and both seemed to improve dye uptake and emphasize YR series color on the surface.

\subsection{Color change according to number of washing} times

To examine color fastness to washing of fabrics which are combination dyed with $0.5 \%$ Juniperus chinensis heartwood extract and $60 \%$ Alnus japonica heartwood extract, dyed cotton and silk were washed repeatedly, and variations in $\mathrm{K} / \mathrm{S}$ value are recorded in Fig. 4 and Fig. 5. And to see variations in color according to repeated washing, $\Delta \mathrm{E}$ value is shown in Table 6 .

In Fig. 4, K/S value of cotton dyed only with Juniperus chinensis heartwood extract didn't show much change after washing, but that of cotton dyed only with Alnus japonica heartwood extract showed decrease after first washing and remained constant. In terms of combination dyeing, as number of times washed increased, K/S value fluctuated by increasing and decreasing, but there was no significant difference. However, there seemed to be little bit of increase in K/S value after 5 times of washing compared to that of before the washing. As in Fig. 5, K/S value of silk dyed only with either of the extracts showed constant decrease as number of times washed increased. When silk was combination dyed using method $1, \mathrm{~K} / \mathrm{S}$ value constantly decreased as number of times washed increased. In terms of combination dyeing using method 2, it fluctuated, but when silk was dyed with dye Alnus japonica heartwood and Juniperus chinensis heartwood extract sequentially, K/S value after the washing was overall higher than that before the washing, so stronger color showed up.

$\Delta \mathrm{E}$ value after repeated washing of combination dyed fabrics is shown in Table 7. $\Delta \mathrm{E}$ value of cotton dyed only with Juniperus chinensis heartwood extract or Alnus japonica heartwood extract

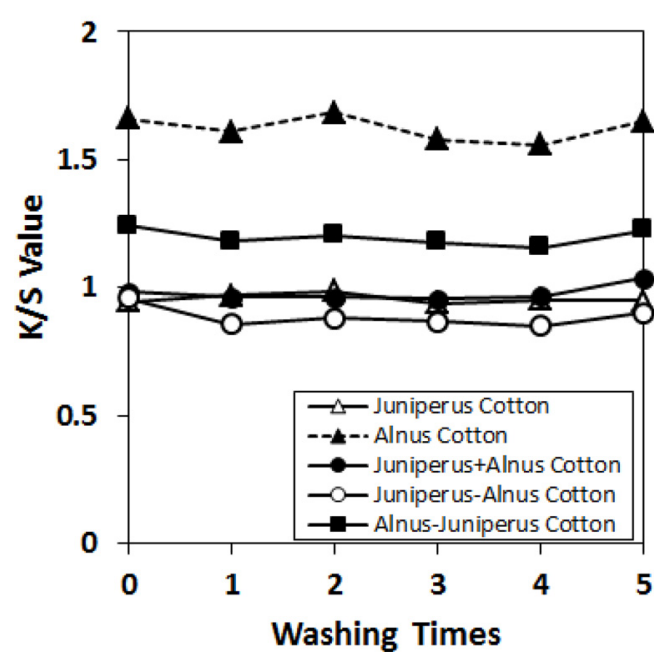

Fig. 4. Effect of washing on the K/S value of cotton fabric dyed with Juniperus chinensis and 60\% Alnus japonica extracts.

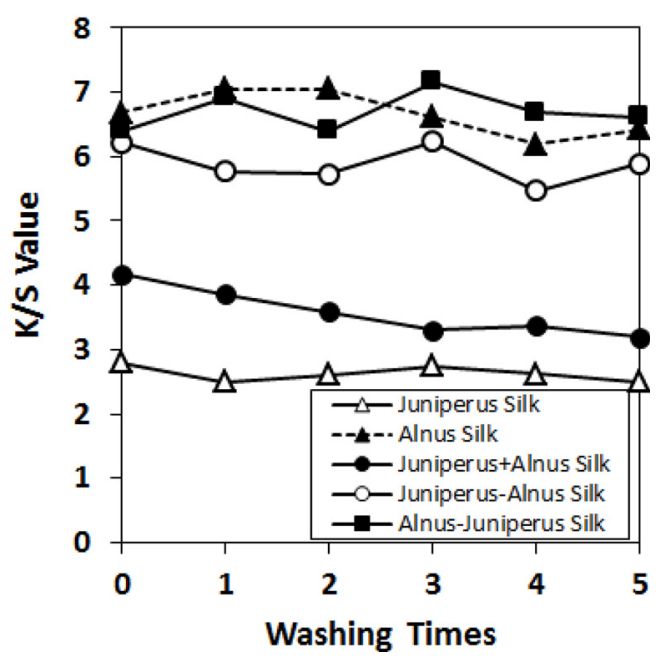

Fig. 5. Effect of washing on the K/S value of silk fabric dyed with Juniperus chinensis and 60\% Alnus japonica extracts. 
Table 7. $\Delta \mathrm{E}$ value of fabrics dyed with Juniperus chinensis and $60 \%$ Alnus japonica extracts after washing

\begin{tabular}{|c|c|c|c|c|c|c|c|c|}
\hline \multirow{2}{*}{ Fabric } & \multirow{2}{*}{ Dyeing method } & \multicolumn{5}{|c|}{ Washing times } & \multicolumn{2}{|c|}{ Color image } \\
\hline & & 1 & 2 & 3 & 4 & 5 & Before washing & After 5times washing \\
\hline \multirow{5}{*}{ Cotton } & Juniperus & 1.523 & 3.000 & 3.338 & 4.115 & 4.917 & & \\
\hline & Alnus & 1.745 & 1.684 & 2.351 & 3.393 & 3.434 & & \\
\hline & Juniperus + Alnus & 0.467 & 1.212 & 2.076 & 3.175 & 3.513 & & \\
\hline & Juniperus-Alnus & 0.822 & 1.424 & 1.805 & 2.581 & 2.586 & & \\
\hline & Alnus-Juniperus & 1.299 & 2.457 & 3.429 & 4.828 & 4.941 & & \\
\hline \multirow{5}{*}{ Silk } & Juniperus & 2.801 & 2.401 & 2.401 & 1.224 & 2.215 & & \\
\hline & Alnus & 6.215 & 2.489 & 2.489 & 0.572 & 2.217 & & \\
\hline & Juniperus + Alnus & 4.179 & 1.390 & 1.390 & 4.292 & 3.623 & & \\
\hline & Juniperus-Alnus & 6.676 & 1.207 & 1.207 & 1.097 & 0.853 & & \\
\hline & Alnus-Juniperus & 6.401 & 1.281 & 1.281 & 1.490 & 0.782 & & \\
\hline
\end{tabular}

was 3.4 and 4.9 respectively after 5 times of washing. $\Delta \mathrm{E}$ of cotton combination dyed using method 2, Juniperus chinensis heartwood extract being the first dye, was 2.6 after 5 times of washing. And the other 2 methods resulted in same trend with the single dyes. For cotton, combination dyeing Juniperus chinensis heartwood extract first and then dyeing Alnus japonica heartwood extract sequentially seemed to decrease color change and decolorization from washing.

Regarding $\Delta \mathrm{E}$ value of silk dyed only with Juniperus chinensis heartwood extract or Alnus japonica heartwood extract was 3.6 and 1.6 respectively after 5 times of washing. When silk was combination dyed, $\Delta \mathrm{E}$ value was 5 in method 1 , and $0.6,1.3$ in method 2 . Therefore, for silk, combination dyeing using method 2 seemed to decrease color change and decolorization from washing.

\subsection{Color change according to UV irradiation}

Variation of K/S value of cotton and silk dyed with Juniperus chinensis heartwood extract and Alnus japonica heartwood extract by UV irradiation is recorded in Fig. 6 and Fig. 7. And to check color variation according to $\mathrm{UV}$ irradiation, $\Delta \mathrm{E}$ value is shown in Table 7.

In Fig. 6, K/S value of dyed cotton mostly increased until irradiation time became 20 minutes, but it decreased slowly after that. It was assumed that at first the $\mathrm{K} / \mathrm{S}$ value of cotton fabric increased by maillard browning of tannin, decreased by fading after a certain amount of time. However, no specific mechanism was proved for this phenomenon(Nam \& Lee, 2011). However, K/S value of cotton dyed with Juniperus chinensis heartwood extract first and then dyed with Alnus japonica heartwood extract increased until irradiation time became 40 minutes, and it remained same after that which indicates there's little change in color. Meanwhile, as seen in Fig. 7, K/S value of dyed silk increased constantly as UV irradiation time increased, and this means darkness in color due to browning reaction caused by sunlight.
By looking at $\Delta \mathrm{E}$ value after the $\mathrm{UV}$ examination in Table $8, \Delta \mathrm{E}$ value of cotton dyed only with Juniperus chinensis heartwood extract increased as UV examination time increased, so $\Delta \mathrm{E}$ value was 10 after 100 minutes of $U V$ examination. However, $\Delta \mathrm{E}$ value of cotton dyed only with Alnus japonica heartwood extract decreased as UV examination time increased, so it became 1.8 after 100 minutes. This indicates Alnus japonica heartwood extract has color fastness to sunlight, and therefore by dyeing Alnus japonica heartwood extract, it is possible for fabrics to improve color fastness to sunlight. And actually, when cotton was combination dyed with Alnus japonica heartwood extract, it had lower $\Delta \mathrm{E}$ value after the UV examination compared to cotton dyed only with Juniperus chinensis heartwood extract. Especially when cotton was dyed with Juniperus chinensis heartwood extract first and then dyed with Alnus japonica heartwood extract sequentially, $\Delta \mathrm{E}$ value was 4.4 after 100 minutes of UV examination. Therefore for cotton, this

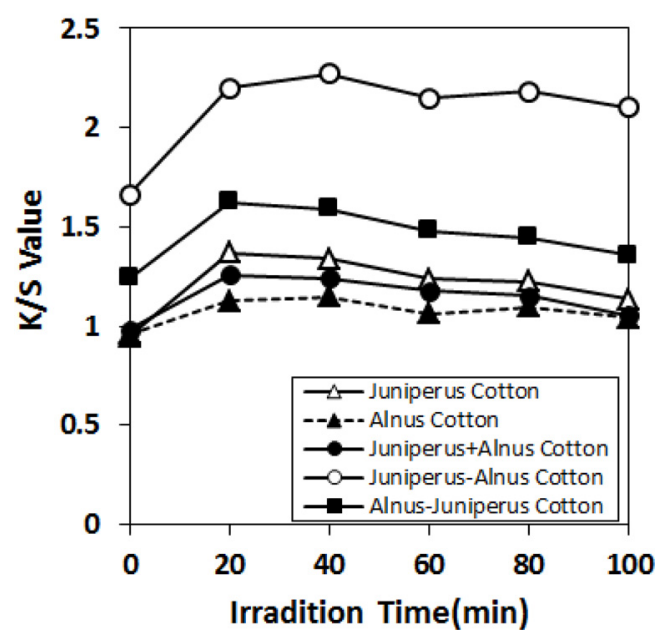

Fig. 6. Effect of UV irradiation on the K/S value of cotton fabric dyed with Juniperus chinensis and 60\% Alnus japonica extracts. 


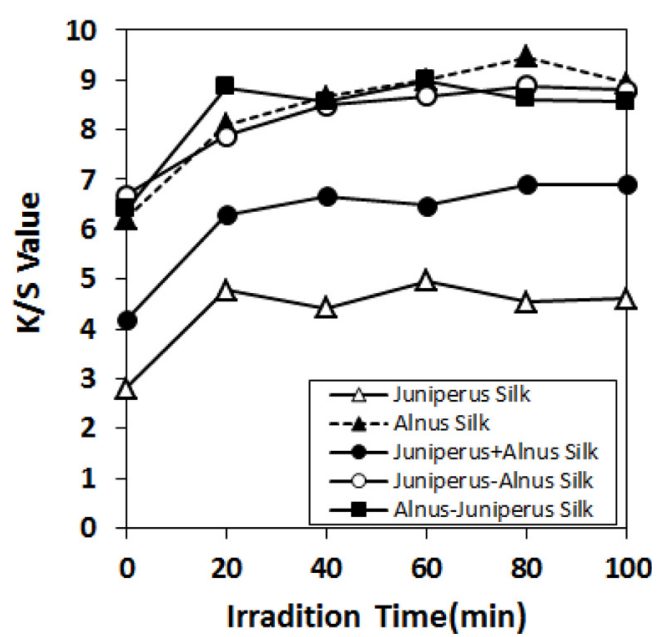

Fig. 7. Effect of UV irradiation on the K/S value of silk fabric dyed with Juniperus chinensis and $60 \%$ Alnus japonica extracts.

method and order of combination dyeing can decrease the color change and decolorization by UV examination. In terms of silk, when combination dyed using Alnus japonica heartwood extract and Juniperus chinensis heartwood extract, $\Delta \mathrm{E}$ value was 8 in method 1, 3.9 and 4.7 in method 2 respectively, while it was 11.92 when single dyed using Juniperus chinensis heartwood extract only. So as in cotton, E value of silk was also smaller when it was combination dyed. Therefore for silk, combination dyeing using method 2 can decrease the color change and decolorization by UV examination.

\section{Conclusion}

Following conclusions are drawn by examining improvements in dye uptake, revelation of various colors, and color fastness to washing and lighting by doing the combination dyeing of Junipe- rus chinensis heartwood and Alnus japonica heartwood extracts.

1. When combination dyeing of Juniperus chinensis heartwood and Alnus japonica heartwood extracts was done using one-bath dyeing and two-bath dyeing, two-bath dyeing was more effective in improving dye uptake than one-bath dyeing. For cotton, dyeing Juniperus chinensis heartwood extract first and then dyeing Alnus japonica heartwood extract sequentially showed higher dye uptake in the two-bath method, while for silk, there wasn't much difference in the dyeing order.

2. When combination dyeing was done using mixed solution of both extracts(one-bath dyeing) and using Juniperus chinensis heartwood extract as a first dye in two-bath dyeing, fabrics were influenced by Alnus japonica heartwood extract more, and thus Y series color showed up. However, when Alnus japonica heartwood extract was dyed first in two-bath dyeing, fabrics were influenced by Juniperus chinensis heartwood extract more, and thus R series and YR series color showed up.

3. In terms of cotton, as number of times washed increased, its $\mathrm{K} / \mathrm{S}$ value fluctuated, but didn't show much variation. In case of combination dyed silk, K/S value decreased when one-bath dyeing was used, and increased when two-bath dyeing was used. But fabrics combination dyed with Juniperus chinensis heartwood extract and Alnus japonica heartwood extract had smaller E value compared to those dyed only with Juniperus chinensis heartwood extract, which indicates combination dyeing is effective in decreasing color change and fading from washing.

4. As UV irradiation time increased, $\mathrm{K} / \mathrm{S}$ value of combination dyed cotton increased and then decreased, and $\mathrm{K} / \mathrm{S}$ value of combination dyed silk increased, but their variation was smaller than that of E value of fabrics dyed only with Juniperus chinensis heartwood extract, so it is considered combination dyed fabrics maintain its color while showing stronger color.

Table 8. $\Delta \mathrm{E}$ value of fabrics dyed with Juniperus chinensis and $60 \%$ Alnus japonica extracts after UV irradiation

\begin{tabular}{|c|c|c|c|c|c|c|c|c|}
\hline \multirow{2}{*}{ Fabric } & \multirow{2}{*}{ Dyeing method } & \multicolumn{5}{|c|}{ Irradiation time } & \multicolumn{2}{|c|}{ Color image } \\
\hline & & 20 & 40 & 60 & 80 & 100 & Before UV irradiation & After 5times UV irradiation \\
\hline \multirow{5}{*}{ Cotton } & Juniperus & 8.746 & 9.206 & 9.600 & 9.665 & 10.01 & & \\
\hline & Alnus & 2.163 & 2.378 & 1.862 & 1.962 & 1.751 & & \\
\hline & Juniperus + Alnus & 5.200 & 5.354 & 5.475 & 5.387 & 5.907 & & \\
\hline & Juniperus-Alnus & 4.142 & 4.516 & 4.399 & 4.442 & 4.385 & & 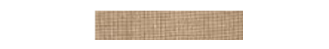 \\
\hline & Alnus-Juniperus & 7.520 & 7.996 & 8.458 & 8.638 & 9.038 & & \\
\hline \multirow{5}{*}{ Silk } & Juniperus & 9.074 & 9.815 & 10.74 & 11.31 & 11.92 & & \\
\hline & Alnus & 2.665 & 3.197 & 3.312 & 4.304 & 3.255 & & \\
\hline & Juniperus + Alnus & 6.178 & 6.945 & 7.655 & 7.804 & 8.028 & & \\
\hline & Juniperus-Alnus & 2.682 & 3.193 & 3.509 & 3.779 & 3.983 & & \\
\hline & Alnus-Juniperus & 4.238 & 3.823 & 4.390 & 4.352 & 4.671 & & \\
\hline
\end{tabular}




\section{Acknowledgements}

This research was supported by Basic Science Research Program through the National Research Foundation of Korea (NRF) funded by the Ministry of Education, Science and Technol$\operatorname{ogy}(2011-0013869)$.

\section{References}

Bae, J. S. (2009). Fabric dyeing with Indigo and Japanese Pagoda tree for color mixture(I)-treatment on cellulose fabrics-. Journal of the Korean Society of Dyers and Finishers, 21(2), 29-39.

Bae, Y. H. (2005). A study on combination-dyeing of yellow and red natural dyes. Unpublished master's thesis, Seoul National University, Seoul.

Choi, H. Y., \& Lee, J. S. (2005). Surface modification of PET irradiated by Ultra-Violet (Part1)-transformation of chemical structure and surface properties-. Journal of the Korean Society of Clothing and Textiles, 29(3/4), 561-568.

Choi, S. C., \& Kim, M. S. (1998). Studies on the dyeing properties of silk and cotton fabrics with Alnus Firma fruit extract. Journal of the Korean Fiber Society, 35(3), 161-173.

Fang, J. M., Chen, Y. C., Wang, B. W., \& Chen, Y. S. (1996). Terpens from heartwood of Juniperus chinensis. Phytochemistry, 4l(5), 1361-1365.

Giles, C. H. (1957). The light fastness of dyed fiber-A statistical study. Journal of the Society of Dyers Colourists, 73(4), 127-160.

Han, Y. S., Yoo, H. J., \& Lee, H. J. (2006). The characteristics of mixed dyeing using Persimmons juice and Onion outer skin extract. Journal of the Korean Society of Clothing and Textiles, 30(1), 115-124.

Hwang, C. I. (1994). The study of Juniper's complex components influence on the atmospheric microorganism and a harmful insect. Unpublished master's thesis, Chosun University, Gwangju.

Jung, J. S., \& Sul, J. H. (2002). Color development of combination dyeing Indian Indigo and Turmeric extracts, Cardenia extracts. Journal of the Korean Society of Clothing and Textiles, 26(2), 325336.

Jung, S. K. (2008). Improvement of lightfastness of fabrics dyed with natural colorants by combination dyeing: Safflower red and Amur Cork tree extract. Unpublished doctoral dissertation, Pusan National University, Busan.

Jung, S. Y., \& Jang, J. D. (2004). Light fastness of silk fabric dyed with Safflower and Amur Cork tree extract for combination dyeing. Journal of the Korean Society of Dyers and Finishers, 16(5), 8-18.

Kang, I. S., Song, H. S., Yoo, H S., Lee, J. S., \& Jung, H. W. (2011). 염색의 이해 [Uderstanding of Dyeing]. Paju: Kyomunsa.

Kim, S. Y. (2009). Color change of combination dyeing of Safflower, Gromwell and Sappan wood. Fashion \& Textile Research Journal, 11(6), 968-973.

Kim, T. H. (2001). Studies on the several biological activities of the extracts from Juniperus chinensis L. and Juniperus rigida Sieb. Unpublished master's thesis, Kangwon National University, Chuncheon.

Kim, Y. M. (2010). A study on combination dyeing of green natural dyes. Unpublished master's thesis, Hongik University, Seoul.

Lee, Y. S., \& Jang, J. D. (2003). The dyeing properties of silk fabric of leaf mustard (Brassica Juncea) extract. Fashion \& Textile Research Journal, 5(4), 389-394.

Lim, K. Y., Jeon, T. J., Yoon, K. J., \& Eom, S. I. (2001). A study on the dyeing characteristics of natural dyes(II)-expansion of color range of natural dyes by mordanting and combination dyeing-. Journal of the Korean Fiber Society, 38(11), 577-588.

Nam, J. R., \& Lee, J. S. (2013). Combination dyeing of silk fabrics with Dansam and Sappan wood. Textile Coloration and Finishing, 25(4), 314-326.

Nam, K. Y., \& Lee, J. S. (2011). Effect of UV Irradiation on the color and mechanical properties of Catechu dyed fabrics. Korean Journal of Human Ecology, 20(5), 1009-1023.

Nam, K. Y., \& Lee, J. S. (2012). Characteristics and dyeability of Juniperus Chinensis extracts. Korean Journal of Human Ecology, 2l(5), 989-1004.

Nam, K. Y., \& Lee, J. S. (2013). Dyeing properties and functionality of methanol extract from Juniperus chinensis heartwood. Textile Coloration and Finishing, 21(3), 194-205.

Noh, E. H., \& Yu, E. K. (2002). The research of compound dyes from natural dyes. Journal of Korea Society of Art and Design, 5(1), 8799.

Noh, Y. J., \& Lee, S. H. (2014). Natural dyeing of soybean protein fabrics-gallnut-. Fashion \& Textile Research Journal, 16(3), 462468. doi:10.5805/SFTI.2014.16.3.462

Oh, S. G., Lee, K. B., Choi, T. H., Yoo, S. I., \& Jung, H. W. (2008). 혼합염색에 관한 연구-황색계열과 청색계열을 중심으로 [A study of combination dyeing-focused on yellow series and blue series]. Proceeding of Korea Technical Association of the Pulp and Paper Industry, Fall Conference, Korea, pp. 165170.

Park, M. O., \& Yoon, S. L. (2011). Properties of natural dyeing of bast fiber.(part3) combination dyeing of Gallnut-sappan wood and gardenia. Journal of Korea Technical Association of the Pulp and Paper Industry, 43(1), 1-10.

Park, Y. H. (2012). A study on the purchase appraisal standard and satisfaction of natural dyeing products. Fashion \& Textile Research Journal, 14(1), 44-74. doi:10.5805/KSCI.2012.14.1.064

Sa, A. N., Choi, H. J., \& Lee, J. S. (2013). Dyeing properties and functionalities of Alnus japonica bark and heartwood extracts. Journal of the Korean Fiber Society, 50(5), 283-291. doi: 10.12772/TSE.2013.50.283

Sa, A. N., Choi. H. J., \& Lee, J. S. (2014). Combination dyeing of Juniperus Chinensis and Terminalia Chebula Retzius. Journal of the Korean Society of Clothing and Textiles, 38(3), 415-426. doi:10.5850/JKSCT.2014.38.3.415

Seo, B. I. (2003). A philological study on Alnui Japonicae Ramulus et cortex. Journal of Applied Oriental Medicine, 3(1), 63-68.

Shin, Y. J. (2012). A study on the complex dyeing of natural dye. Journal of the Korea Fashion \& Costume Design Association, 14(4), 151-162.

Shin, Y. S., \& Choi, H. (1999). Characteristics and dyeing propreties of green tea colarants(Part1) -Components and characteristics of green tea colarants. Journal of the Korean Society of Clothing and Textiles, 23(1), 140-146.

Sul, J. H., \& Choi, S. C. (1999). A study on tannin treatment of silk 
fabrics(IV) -Changes of properties in tannin treated fabrics-. Journal of the Korean Society of Dyers and Finishers, 11(4), 1623.

Sul, J. H., Choi, S. C., \& Cho, K. R. (1995). A study on tannin treatment of silk fabrics(III) -Comparison condensed tannin with hydrlyzed tannin-. Journal of the Korean Society of Dyers and Finishers, 7(3), 60-67.

Tennakone, K., Kumara, G. R. R. A., Kottegoda, I. R. M., Perera, V. P. S., \& Weerasundara, P. S. R. S. (1998). Sensitization of nanoporous films of $\mathrm{TiO} 2$ with Santalin(Red sandalwoodpigment) and construction of dye-sensitized solid-state photovoltaic cells. Journal of Photochemistry and Photobiology A: Chemistry, $117(2), 137-142$.
Yoo, H. J., \& Lee, H. J. (2001). Fabric dyeing with Artemesia and Gardenia for color mixture. Journal of the Korean Society of Dyers and Finishers, 13(6), 16-22.

Yoo, H. J., \& Lee, H. J. (2003). Color-matching of fabrics by natural dyeing using Indigo and Safflower. Journal of the Korean Society of Dyers and Finishers, 15(4), 32-38.

Yoo, H. J., Lee, H. J., Han, Y. S., Song, K. H., Kim, J. H., \& Ahn, C. S. (2014). 섬유의 염색과 가공 [Dyeing and Finishing of Fiber]. Seoul: Hyungseul.

(Received 30 September 2014; 1st Revised 27 November 2014; 2nd Revised 24 December 2014; Accepted 10 February 2015)

(C) 2015 (by) the authors. This article is an open access article distributed under the terms and conditions of the Creative Commons Attribution license (http://creativecommons.org/licenses/by/3.0/), which permits unrestricted use, distribution, and reproduction in any medium, provided the original work is properly cited. 